\title{
Chances and Challenges of Registry-Based Pharmacovigilance in Multiple Sclerosis: Lessons Learnt from the Implementation of the Multicenter REGIMS Registry
}

\author{
Alexandra Simbrich ${ }^{1}$ (D) Jasmine Thibaut ${ }^{1} \cdot$ Laura Khil $^{1,2} \cdot$ Stanislav Maximov $^{1} \cdot$ Heinz Wiendl $^{3} \cdot$ Klaus Berger $^{1}$ on \\ behalf of for the REGIMS Investigators
}

Accepted: 27 September 2020 / Published online: 23 October 2020

(c) The Author(s) 2020

\begin{abstract}
The long-term and potential rare side effects of new immunomodulating drugs for the treatment of multiple sclerosis (MS) are often not well known. Spontaneous case report systems of adverse drug effects are a valuable source in pharmacovigilance, but have several limitations. Primary data collections within registries allow a comprehensive analysis of potential side effects, but face several challenges. This article will outline the chances and challenges of registry-based adverse event reporting, using the example of the German immunotherapeutic registry REGIMS. REGIMS is an observational, clinical multicenter registry that aims to assess the incidence, type, and consequences of side effects of MS immunotherapies. Patients treated with an approved MS medication are recruited by their physicians during routine visits in hospitals, outpatient clinics, and MS-specialized practices. REGIMS incorporates an electronic physician-based documentation in each center and a paperbased patient documentation, both at baseline and regular follow-up visits. By the end of 2019, 43 REGIMS centers were actively recruiting patients and performing follow-up documentations. The majority of the first 1000 REGIMS patients were female (69.3\%), had relapse-remitting MS (89.8\%), and were treated with a second-line therapy. During the implementation of REGIMS, several logistic and procedural challenges had to be overcome, which are outlined in this paper. Pharmacovigilance registries such as REGIMS provide high-quality primary data from a specific patient population in a real-world care setting and enable pharmacovigilance research that cannot be carried out using secondary data. Despite the logistic and procedural challenges in establishing a multicenter pharmacovigilance registry in Germany, the advantages outweigh the drawbacks.
\end{abstract}

\section{Key Points}

Alexandra Simbrich and Jasmine Thibaut have shared first authorship/are equally contributing authors.

The members of the REGIMS Investigators are mentioned in the Acknowledgements section.

Electronic supplementary material The online version of this article (https://doi.org/10.1007/s40264-020-01007-1) contains supplementary material, which is available to authorized users.

Alexandra Simbrich

simbrich@uni-muenster.de

1 Institute of Epidemiology and Social Medicine, University of Münster, Münster, Germany

2 Cancer Registry of North Rhine-Westphalia, Bochum, Germany

3 Department of Neurology with Institute of Translational Neurology, University of Münster, Münster, Germany
The implementation of a multicenter pharmacovigilance registry such as REGIMS into routine clinical care faces multiple challenges that must be addressed and solved in the planning phase. Among them is the motivation of centers and participants, the IT architecture of data collection, and changes in data items over time.

Registry-based data assessment allows the safety monitoring of highly specialized drugs for which there is limited experience, especially with regard to their longterm use.

Information on patient-reported outcomes ideally complements the medical documentation and is gaining increasing relevance. 


\section{Introduction}

Multiple sclerosis (MS) is a complex autoimmune neurological disease, often with an age of onset in young adulthood $[1,2]$. Increasing disability during the course of disease and subsequently a reduced life expectancy are frequently observed in patients with MS and result in a high socioeconomic burden for the population [3].

In the last 10 years, many MS treatments aiming to modify different immune functions have been newly approved $[4,5]$, representing a major change to the limited number of treatment options beforehand. In addition, several ongoing phase II and phase III trials in the MS field will most likely lead to further approvals in upcoming years $[6,7]$. However, the long-term effects and potential rare side effects of new treatments, especially when used in routine clinical care, are not well known. Thus, the treatment of MS patients represents an important and interesting field for pharmacovigilance.

Spontaneous reports of adverse drug reactions are an important source of post-marketing drug safety surveillance. However, these reports rely on the alertness and motivation of those who should report, while these individuals often have challenging daily clinical care routines. Spontaneous report systems, such as the German one, also do not provide all the information about a specific exposure to the drug and lack important patient characteristics, such as data on quality of life, therapy adherence, or patients' satisfaction with their medication.

Here, multicenter, longitudinal registries provide a comprehensive design to complement the spontaneous case report system within a given healthcare system. Those registries that are based on primary data collections, such as physician documentation of MS patients on immunomodulatory MS medication, allow an extensive analysis of potential drug side effects. They are ideally complemented by patient self-reports of so-called patient-reported outcomes (PROs), e.g., quality of life perceptions or activities of daily living. Medical documentation should be concise, implementable in the physician's documentation during regular visits, and updated on a regular basis. Avoiding the need for double data entry is another important issue since many different software tools for data entry are available in outpatient services and specialized MS practices, especially in Germany, and center-specific software should be used, whenever possible. However, the implementation of data items in different software tools for routine care imposes high logistic complexity. To date, only a few pharmacovigilance registries in the field of MS have been implemented internationally, and none in Germany.

The aim of this paper is to describe the chances and challenges of registry-based adverse event (AE) reporting and, more generally, in pharmacovigilance, using the REGIMS registry, a German immunotherapeutic registry to improve drug safety in MS therapies, as an example.

\section{Background: The Need for Registry-Based Adverse Event Reporting}

The introduction of new immunomodulatory substances during the last decade, many of them being biologicals, has increased the treatment options for MS significantly. Their use offers a number of opportunities for the treatment of MS, but also carries the risk of side effects. The assessment of side effects (including unexpected and previously unknown AEs) via standardized documentation in routine clinical care is an established method for the data-based risk assessment of new substances, but has not been conducted using a registry-based approach for MS patients in Germany before.

In order to improve the safety of these therapies in the treatment of MS patients and to document side effects of approved MS drugs, the immunotherapy registry REGIMS was established by the disease-oriented Competence Network Multiple Sclerosis (Krankheitsbezogenes Kompetenznetz Multiple Sklerose [KKNMS]), starting in November 2013. The KKNMS was initiated in 2009 and focuses on various research topics that have been addressed by leading experts in the field of MS in nationwide collaborations [8]. The overall goal of REGIMS is to assess the incidence, type, and consequences of adverse drug reactions of current and future MS medications. Secondary aims are to identify patient-related factors that are associated with adverse drug reactions and therapy adherence, to analyze quality of life under therapy, and to investigate the efficacy of new substances in the course of the disease. In addition to the main focus on safety aspects, REGIMS includes a patient questionnaire to collect PROs on a regular basis.

\subsection{Methodological Aspects}

Study Design REGIMS is a national, prospective, observational (i.e., non-interventional), clinical multicenter registry within the KKNMS. Participating centers are KKNMS network centers as well as centers that have been invited to participate in REGIMS if they met the criterion of providing regular outpatient care to MS patients. Overall, the REGIMS centers are made up of clinics, MS outpatient clinics, and MS-specialized practices. Patients with diagnosed MS or with a clinically isolated syndrome (CIS) and treated with an approved MS medication at study baseline are included. The study incorporates physician-based documentation in each center and patient-based documentation, both at baseline and 
at regular follow-ups every 6 months. Study participants are recruited by their treating physicians during routine visits after signing informed consent.

REGIMS is constantly including new centers. By the end of 2019, 43 REGIMS centers were actively recruiting study participants and performing follow-up documentations, with two to four new centers joining the registry every year.

Inclusion Criteria Included in REGIMS are patients with a confirmed diagnosis of MS or with CIS, aged 18 years or older, and who are either:

- Treated de novo with a MS medication.

- Treated with natalizumab, fingolimod, mitoxantrone, alemtuzumab, ocrelizumab, dimethyl fumarate, teriflunomide, or in the future approved immunotherapeutic drugs, independent of therapy duration.

- Treated with interferon- $\beta-1$ a administered intramuscularly (IM)/subcutaneously (SC), interferon- $\beta$-1b SC, glatiramer acetate, or azathioprine for a maximum of 36 months.

Exclusion Criteria Excluded from REGIMS are patients under 18 years, patients without a definite diagnosis of MS (except for CIS patients), and patients treated with interferon- $\beta$ - $1 \mathrm{a}$ IM/SC, interferon- $\beta$ - $1 \mathrm{~b}$ SC, glatiramer acetate, or azathioprine for more than 36 months.

Ethical and Data Protection Issues Patients who meet the inclusion criteria receive written information about the registry and sign informed consent, which has been approved by local ethics committees. The patient consent includes the collection and storage of medical data including AEs, the use of these data for scientific analyses, and the storage of personal data (e.g., name and address) that are necessary for the administration of the patient-based documentation (paper-based questionnaires).

Ethical approval was initially obtained by one ethics committee (so-called main approval), with subsequent approval by multiple ethics committees across all German federal states. Patients can withdraw their consent in the documentation at any time.

Only pseudonymized data are stored in the REGIMS database. Personal data are not submitted to the database and thus are not available for the scientists carrying out scientific analyses. However, personal data (e.g., name and address) are necessary for the administration of the patientbased documentation and are only accessible to authorized staff who administers the mailing of the paper-based questionnaires and who do not have access to the data from the medical documentation. These personal data are stored separately from the medical documentation and from the questionnaires.

\subsection{Data Collection in REGIMS}

Physician-Based Documentation (Electronic Documentation in the Centers) The physician-based documentation (medical documentation) is done during routine patient visits in the centers. The registry has five different software tools for data entry, enabling centers to decide which to use based on local needs and infrastructure and to reduce the need for double data entry. These web data entry tools are REDCap, Secutrial ${ }^{\circledR}$, MSDS $^{\circledR}$, x4T-EDC System (REGIMS platform), and the web-based tool of the German MS Society (Deutsche Multiple Sklerose-Gesellschaft [DMSG]). For consenting patients, the physician-based documentation is done electronically in one of these software tools. From each tool, exports of the REGIMS data via interfaces are done on a regular basis, and after verification, data from the different software tools are merged in the study database.

Patient-Based Documentation (Paper-Based Questionnaires) In addition, a paper-based questionnaire with information on PROs is completed by the patients and sent back to the REGIMS coordination center twice in the first 12 months and annually thereafter. There, all questionnaires are scanned; data are checked for plausibility and subsequently imported into the database. Patient self-reports include quality of life, healthcare utilization, treatment satisfaction, and adherence, as well as different scales for psychosocial functions. Table 1 summarizes in detail items assessed at baseline and at follow-up visits stratified by documentation type (physician vs. patient).

Documentation of Safety Data AEs or serious adverse events (SAEs) can be reported to REGIMS at every routine follow-up visit in the center, irrespective of causality. In this case, documentation includes a detailed questionnaire regarding information on AEs and a rating of causality. AE and SAE documentation in the REGIMS registry is not limited to events with at least some degree of suspected causal association, i.e., the study nurses and physicians are asked to report all events, even if they rate the causality for an AE as "not assessable," "unlikely," or "not related." SAEs are immediately sent to REGIMS via the software and reported to the marketing authorization holder within $24 \mathrm{~h}$, thus, complementing the German spontaneous case report system. Safety reports are prepared according to European guidelines and sent to all centers every 6 months.

Quality Assurance and Data Management All participating study nurses and physicians in the REGIMS centers receive on-site training in data entry in order to ensure high data quality. Additionally, the web-based documentation performs automated data checks for completeness and plausibility during data entry. The processing of paperbased patient questionnaires includes plausibility and completeness checks. 
Table 1 Electronic and patient-based documentation in REGIMS

\begin{tabular}{lll}
\hline & Baseline & Follow-ups \\
\hline $\begin{array}{ll}\text { Physician documentation (electronic } \\
\text { documentation in the centers) }\end{array}$ & Demographic characteristics & EDSS \\
& EDSS & Changes in MS type \\
& MS type + prior course & Changes + reasons for change in MS \\
& Current and previous MS-medication & AE/SAE \\
& Comorbidities & Relapses \\
& Pregnancy & Pregnancy \\
Patient documentation (paper-based question- & Family history of MS & SF-36 \\
naires at home) & SF-36 & EQ-5D \\
& satisfaction with efficacy and safety of MS & Satisfaction with efficacy and safety of MS \\
& medication & medication \\
& Medication of last 7 days & Medication of last 7 days \\
& Healthcare utilization & AE/SAE \\
& PHQ-9, GAD-7 & Relapses \\
& & Healthcare utilization \\
& & PHQ-9, GAD-7, RS-11
\end{tabular}

$A E$ adverse event, $E D S S$ expanded disability status scale, $G A D-7$ Generalized Anxiety Disorder 7 questionnaire, $M S$ multiple sclerosis, $P H Q-9$ Patient Health Questionnaire, RS-11 11-item Resilience Scale, SAE serious adverse event, SF-36 36-item Short Form Health Survey

\section{Registry Participants in REGIMS until 2019}

By the end of 2019, 1562 patients had been included in the REGIMS registry, of whom 1283 patients already had at least one follow-up available.

Descriptive characteristics of the first 1000 patients included in REGIMS are shown in Tables 2 and 3. The average age at baseline documentation was 38.4 years, with a mean age at diagnosis of 31.0 years. The majority of the patients were female, most had relapse-remitting MS (89.8\%), and the median expanded disability status scale (EDSS) score was 2.5. Most patients were treated with a second-line therapy. Physician-based follow-up documentation was conducted with a median follow-up time of 5.8 months (Table 2). Natalizumab (33.1\%) was the most frequently administered drug at baseline assessment, followed by fingolimod $(21.7 \%)$, alemtuzumab (15.9\%), dimethyl fumarate (10.1\%), ocrelizumab (5.3\%), interferons $(4.4 \%)$, teriflunomide $(3.5 \%)$, and glatiramer acetate $(3.4 \%$ ) (Table 3$)$.

The median number of patient-reported MS onset symptoms was two, with dysesthesias (53.3\%), motor disturbances $(53.0 \%)$, and impaired vision $(44.4 \%)$ being the most frequent onset symptoms (Table 2). About two thirds $(68.6 \%)$ of the patients had at least one comorbidity. Allergies (26.7\%), depression (15.7\%), and hypertension (14.6\%) were the most frequently reported comorbidities (Table 3).

\section{Discussion}

Experiences gained during the implementation of the REGIMS registry and the results of the first 1000 included patients described previously can be used to address, more generally, the chances and challenges that have to be met if prospective registries are built for pharmacovigilance purposes. This is discussed in more detail below.

The Relevance of Pharmacovigilance Registries The important role of primary data collections within pharmacovigilance registries such as REGIMS is emerging since they provide high-quality data from a specific patient population in a real-world care setting. Furthermore, they provide information about drug safety or PROs, and can address different research questions regarding pharmacovigilance. In addition, pharmacovigilance registry data are able to disentangle potential causal outcomes such as a relationship between treatment with a highly effective drug and an AE. Pharmacovigilance registries with a long-standing history and tightly monitored data collection, such as the Swedish MS registry (SMSreg), the German biologics registry RABBIT, or the Swedish biologics registry ARTIS, have highlighted the clinical relevance of primary data for monitoring drug safety [9-12]. Data from these registries provide valuable information on pharmacovigilance issues that may not be detected using secondary data, and add complementary information to findings from randomized controlled trials that underrepresent or do not include specific patient 
Table 2 Descriptive characteristics of the first 1000 REGIMS participants at baseline

\begin{tabular}{ll}
\hline Baseline characteristics & $n=1000$ \\
\hline Age in years [mean (SD)] & $38.4(11.2)$ \\
Age in years at MS diagnosis [mean (SD)] & $31.0(10.7)$ \\
Disease duration in years [mean (SD)] & $7.3(6.7)$ \\
Follow-up time in months [median (SD)] & $5.8(2.2)$ \\
Women (\%) & 69.3 \\
Never-smoker ${ }^{\mathrm{a}} \%$ ) & 43.1 \\
Ex-smoker ${ }^{\mathrm{a}}(\%)$ & 25.4 \\
Current smoker ${ }^{\mathrm{a}}(\%)$ & 31.5 \\
Clinical course & \\
CIS (\%) & 1.1 \\
RRMS (\%) & 89.8 \\
PPMS (\%) & 2.3 \\
SPMS (\%) & 2.0 \\
Not determined/unknown (\%) & 4.7 \\
EDSS score, median (IQR) & $2.5(2.5)$ \\
Number of relapses during last 24 months, median (IQR) & $1.0(2.0)$ \\
Number of reported onset symptoms, median (IQR) & $2.0(2.0)$ \\
MS onset symptoms ${ }^{\mathrm{a}}$ & \\
Dysesthesias (\%) & 53.3 \\
Motor disturbances (\%) & 53.0 \\
Impaired vision (\%) & 44.4 \\
Exhaustibility (\%) & 25.5 \\
Concentration or memory problems (\%) & 11.2 \\
Bladder dysfunctions (\%) & 10.3 \\
Depressed mood (\%) & 7.7 \\
Tremor (\%) & 6.5 \\
Hearing impairment/speech problems/dysphagia (\%) & 5.5 \\
Sexual disturbances (\%) & 3.4 \\
Bowel voiding dysfunction (\%) & 3.4 \\
Euphoric mood (\%) & \\
\hline
\end{tabular}

$C I S$ clinically isolated syndrome, EDSS expanded disability status scale, $I Q R$ interquartile range, $M S$ multiple sclerosis, $P P M S$ primary progressive multiple sclerosis, $R R M S$ relapse-remitting multiple sclerosis, $S D$ standard deviation, SPMS secondary progressive multiple sclerosis

${ }^{\text {a } P a t i e n t-r e p o r t e d ~ i n f o r m a t i o n ~}$

subgroups $[13,14]$. However, the implementation of a multicenter registry such as REGIMS into routine clinical care is accompanied by multiple chances and challenges. Experiences with implementing and running the pharmacovigilance registry REGIMS will be outlined in this section.

Ethical Approval and Judicial Contracts Due to Germany's federal structure, difficulties regarding administrative modalities occurred. The study had initially been approved by one ethics committee (main approval). However, every ethical board responsible for one or more participating centers in each state had to accept this approval independently because a centralized approval process only exists for
Table 3 Therapies and comorbidities of the first 1000 REGIMS participants at baseline

\begin{tabular}{ll}
\hline Number of prior MS therapies, median (IQR) & $1.0(1.0)$ \\
Duration of current MS therapy in years, median (IQR) & $1.0(2.0)$ \\
MS therapy at baseline & \\
Natalizumab (\%) & 33.1 \\
Fingolimod (\%) & 21.7 \\
Alemtuzumab (\%) & 15.9 \\
Dimethyl fumarate (\%) & 10.1 \\
Ocrelizumab (\%) & 5.3 \\
Interferons (\%) & 4.4 \\
Teriflunomide (\%) & 3.5 \\
Glatiramer acetate (\%) & 3.4 \\
Other (\%) & 2.6 \\
Comorbidities & \\
Number of reported comorbidities, median (IQR) & $1(3)$ \\
Allergies (\%) & 26.7 \\
Depression (\%) & 15.7 \\
Hypertension (\%) & 14.6 \\
Migraine and/or tension type headache (\%) & 13.0 \\
Hypo- or hyperthyroidism (\%) & 11.7 \\
Herpes infection (\%) & 10.2 \\
Hair loss (\%) & 5.9 \\
Recurring urinary tract infection (\%) & 4.7 \\
Arthralgia (\%) & 3.9 \\
Cardiac arrhythmias (\%) & 2.6 \\
Other autoimmune diseases (\%) & 2.2 \\
Diabetes mellitus (\%) & 2.0 \\
Cancer (\%) & 1.6 \\
\hline
\end{tabular}

$I Q R$ interquartile range, $M S$ multiple sclerosis

clinical trials. Since university hospitals in Germany usually have their own ethical board, neighboring centers might have required two different approvals. This led to a timeconsuming procedure for ethical approval and registration of every new center, and was associated with considerable costs $[15,16]$.

Software Issues The medical electronic documentation should be feasible within the regular physician-based documentation during routine visits, avoiding the necessity for double data entry. This is an issue for any disease since usually different software tools for data entry are available and used in practice. A major strength of REGIMS is that different software tools can be used for the physician-based documentation, giving each center the possibility of using the locally most convenient solution. In addition, software tools are adaptable, e.g., newly approved drugs can rapidly be implemented into the tools. AEs and SAEs can be documented at every routine follow-up visit, irrespective of the visit interval length, providing further flexibility to the centers, as long as a minimum of one assessment is done per year. This ensures that potential associations between 
medication and (S)AEs can be detected at an early time point. The challenge of this approach is that the software maintenance of the different tools that are provided by different companies is logistically complex and cost- and personnel-intensive. Here, two alternative approaches are preferable: implementation of the pharmacovigilance items in the existing practice or hospital software, or limitation of the number of software tools for the pharmacovigilance documentation to the two to three most frequently used ones. The first approach is most convenient for the documenting center, but implies dealing with many different software companies. The latter approach includes double documentation for a small number of patients, but restriction to very few tools.

Recruitment of Centers Center recruitment is an important issue for each new registry. Practices often have a high workload and no possibility of or interest in investing time for patient recruitment for scientific or quality-assurance purposes which are done on an optional basis. However, outpatient services are of high relevance in registries, since patients are seen on a regular basis, and reflect clinical routine care. Motivation strategies to convince centers to participate have to be developed. In this process, financial incentives have to be weighed against nonmonetary advantages. In the REGIMS registry, a combination of incentives is applied. A documentation fee of $€ 50$ is paid for baseline, and $€ 15$ for follow-up documentation (in 2019), respectively. Additionally, AE reports are provided and a newsletter including center-specific recruitment information is sent on a regular basis. The motivation strategy also includes a rising awareness of pharmacovigilance questions in the dynamic MS field.

Recruitment of MS Patients In contrast to clinical trials, it is of high importance in registries to continuously include new patients, and to be as complete as possible. While centers are generally motivated at the beginning, a "motivational pause" after a certain number of patients often occurs, and only follow-up documentation of already included patients is done. There may be many reasons for this observation, but documentation always relies on motivated people, study nurses and physicians in the centers. Thus, recruitment works effectively if integrated into routine clinical practice, which is not feasible in every center, and motivation of the recruiting team is crucial for the development of a registry. Factors that increase motivation are generally short and concise data items, easily implementable into the daily routine process of care with low or no training demands and no documentation reliance on one specific professional group only. In addition, regular feedback on recruited patient numbers and availability of own data are motivating factors.

Selection and Treatment Bias One aim of REGIMS was to document AEs in patients with newly approved immune system modifying treatments. Thus, due to the design of the registry, the majority of REGIMS patients are treated with a second-line therapy at baseline and the proportion of this patient group is higher than in the average German MS population $[2,17]$. Therefore, the majority of the centers recruit patients on highly active drugs that were only approved in recent years (i.e., natalizumab, fingolimod, alemtuzumab, and ocrelizumab) and if they can ensure they can see the patients on a regular basis, e.g., for the administration or monitoring of the treatment. In contrast, patients on interferon, glatiramer acetate, and azathioprine are less often recruited. A potential reason for this selection is that interferon treatment has been well established for many years, with a known side effect profile, and patients are often not seen on a regular basis by a center. But it is important to establish a comparison group within a pharmacovigilance registry to be able to decide if signals or risks in patients on a specific (new) drug are higher than in those on standard or basic treatment. Patients in REGIMS so far may not be representative for the population of German patients treated with MS immunotherapies, and disease severity might be slightly higher among them. However, with respect to basic demographic characteristics and disease characteristics, such as age at disease onset and clinical course of MS, patients in REGIMS are comparable with the German MS population [17-19]. As participation in the REGIMS registry is voluntary for the centers and the patients, there are no data available on the number of patients who were invited at the study sites but refused to participate; hence, we can give no estimate of the overall enrollment. However, the participating centers are asked to inform all eligible MS patients about the registry, and currently there is no upper limit to the number of REGIMS participants.

Patient-Based Documentation Another strength of REGIMS is that the medical documentation is complemented by longitudinal patient self-reports, providing a more detailed assessment of a patient's disease status and living situation over time. It has been shown that non-adherence may occur due to AEs or lack of efficacy of medication [20, 21] or different living situations. This issue may be detected early by patient-based documentation.

Data Quality High-quality data are ensured by standardized procedures regarding data entry via the software tools, plausibility checks during and after data entry, and training of every new study center. Furthermore, communication with and information for the study centers guarantees that centers are always up to date and informed about changes in the organizational or personnel structure of the project.

Creating a Pharmacovigilance Database The main objective of REGIMS is to create a pharmacovigilance database for MS in Germany, which includes safety data and PROs, such as quality of life, treatment adherence, healthcare utilization, and costs for patients. REGIMS assesses the frequency and type of AEs and SAEs across all MS drugs and differs in this respect from clinical observational and/or 
application studies (non-interventional studies) of pharmaceutical companies, which do not allow comparisons across MS drugs and differ from each other in terms of the number and type of documented items. There is also the possibility of an intervention in the case of SAEs, and a cooperation with the responsible authorities can be established. Furthermore, treatment switches, interruptions in treatment, and reasons for switching or interrupting treatment can be analyzed with the REGIMS registry data, which is an advantage over post-marketing surveillance studies and registries implemented by marketing authorization holders, which are usually limited to one drug. The documentation of all AEs irrespective of the causality, i.e., even if causality is rated as "not assessable," "unlikely," or "not related," is a clear strength of REGIMS as it allows the detection of events for which a causal association between the MS drug and the AE had not yet been considered. Our data show that physician-based follow-up documentation was conducted with a median follow-up time of 5.8 months, which allows the documentation of AEs and SAEs on a regular basis.

Other Methodological Issues A limitation might be that the validity of patient-reported information could be an issue. However, as physician-based documentation is also available, this can probably be neglected. Also, since questionnaires are sent to the patients directly, a slight time difference with the physician-based documentation may occur. As in any study, loss to follow-up plays an important role in the analyses and may bias the results. In REGIMS, loss to follow-up is minimized by the use of two different data sources (physician and patient reports). Moreover, the acceptance of the paper-based questionnaires by the patients is high (response rate $>90 \%$ ).

\section{Conclusions}

Studies based on prospective registries, such as the immunotherapy registry REGIMS, represent a fundamental effort in planning, implementing, and logistics. However, the importance of such registry studies for clinical care and research is increasing as they focus on specific patient groups and/or rare diseases. Despite the logistic and procedural issues in establishing such a multicenter pharmacovigilance registry in Germany, the advantages outweigh the drawbacks. Pharmacovigilance registries with standardized data assessment are important for monitoring highly specialized and rapidly changing drugs associated with significant financial costs and with possible AEs or SAEs that can occur after a long treatment period. In addition, data from registries such as the REGIMS registry allow the comparison of AEs and SAEs of newly approved drugs for which there is limited experience, especially regarding their long-term use. It is possible to directly analyze drug history and treatment switches, as well as interruptions in the treatment, to assess therapy adherence and safety and to collect PROs. Future newly approved immune therapies can easily be added into the REGIMS documentation, and its results shall support physicians in finding the most appropriate therapy for a selected patient.

Acknowledgements For the REGIMS Investigators, we would like to thank all the participating patients and neurologists for their support in REGIMS. For the acquisition of data we would like to thank: Prof. Dr. med. Luisa Klotz: Universitätsklinikum Münster, Klinik für Allgemeine Neurologie, Münster; Prof. Dr. med. Florian Stögbauer: Klinikum Osnabrück GmbH, Neurologische Klinik, Osnabrück; Prof. Dr. med. Orhan Aktas: Heinrich-Heine-Universität Düsseldorf, Klinik für Neurologie, Düsseldorf; Prof. Dr. med. Tjalf Ziemssen: Klinikum Carl Gustav Carus, Neurologische Universitätsklinik, Dresden; Prof. Dr. med. Frauke Zipp: Universitätsmedizin Mainz, Klinik und Poliklinik für Neurologie, Mainz; Priv.-Doz. Dr. med. Antonios Bayas: Universitätsklinikum Augsburg, Klinik für Neurologie und klinische Neurophysiologie, Augsburg; Prof. Dr. med. Thomas Müller: St. JosephKrankenhaus Berlin Weißensee, Klinik für Neurologie, Berlin; Prof. Dr. med. Friedemann Paul: Charité - Universitätsmedizin, Exzellenzcluster NeuroCure, Berlin; Dr. med. Maria Seipelt: Philipps-Universität Marburg, Klinik und Poliklinik für Neurologie, Marburg; PD Dr. med. Klemens Angstwurm: Universität Regensburg, Klinik und Poliklinik für Neurologie, Regensburg; Prof. Dr. med. Martin Weber: Universitätsmedizin Göttingen Abteilung Neurologie, Göttingen; Prof. Dr. med. Brigitte Wildemann: Universitätsklinikum Heidelberg, Neurologische Klinik, Heidelberg; Prof. Dr. med. Tania Kümpfel: Klinikum der Universität München, Institut für Klinische Neuroimmunologie, München; Dr. med. Christoph Ruschil: Universität Tübingen, Zentrum für Neurologie, Abteilung Neurologie mit Schwerpunkt neurovaskuläre Erkrankungen, Tübingen; Dr. med. Matthias Grothe: Universitätsmedizin Greifswald, Klinik und Poliklinik für Neurologie, Greifswald; Dr. med. Iris Steck: Medizinisches Versorgungszentrum für Neurologie und Psychiatrie Bremen Nord, Bremen; Prof. Dr. med. Christoph Heesen: Universitätsklinikum Hamburg-Eppendorf, Klinik und Poliklinik für Neurologie, Hamburg; Prof. Dr. med. Uwe Zettl: Universitätsmedizin Rostock, Zentrum für Nervenheilkunde, Klinik und Poliklinik für Neurologie, Rostock; Dr. med. Refik Pul: Universitätsklinikum Essen, Klinik für Neurologie, Essen; Prof. Dr. med. Hayrettin Tumani: Universität Ulm, Klinik und Poliklinik für Neurologie, Ulm; Dr. med. Matthias Kaste: Nordwestkrankenhaus Sanderbusch, Neurologische Klinik, Sande; Dr. med. Frank A. Hoffmann: Krankenhaus MarthaMaria Halle-Dölau gGmbH, Klinik für Neurologie, Halle/Saale; Prof. Dr. med. Wolfgang Freund: Gemeinschaftspraxis Dr. Nonn \& Prof. Dr. Freund, Biberach; Prof. Dr. med. Peter Schwenkreis: BG-Universitätsklinikum Bergmannsheil Bochum, Neurologische Universitätsklinik und Poliklinik, Bochum; Dr. med. Annette Walter: Klinikum Herford, Klinik für Neurologie, Herford; Dr. med. Frank Halbgewachs: Neurologische Praxis Heidenheim Dr. Krüger - Dr. Halbgewachs - Dr. Breitinger, Heidenheim; Dr. med. Florian Bethke: Klinikum Ibbenbüren, Klinik für Neurologie, Ibbenbüren; Dr. med. Michael Hotz: Christliches Krankenhaus Quakenbrück, Neurologische Klinik, Quakenbrück; Dr. med. Stefan Harscher: Sophien- und HufelandKlinikum gGmbH Weimar, Klinik für Neurologie, Weimar; Dr. med. Ralf-Jochen Kuhlmann: Evangelisches Krankenhaus Castrop-Rauxel, Klinik für Neurologie, Castrop-Rauxel; Dr. med. Cordula Haltenhof: Ammerland Klinik GmbH, Klinik für Neurologie, Westerstede; Dr. med. Muhterem Erinola: Katholisches Klinikum Lünen/Werne GmbH, Neurologische Klinik, Lünen; Prof. Dr. med. Jörg Berrouschot: Klinikum Altenburger Land GmbH, Klinik für Neurologie, Altenburg; Dr. med. Isabell Greeve: Evangelisches Krankenhaus Bielefeld, Klinik für Neurologie, Bielefeld; Dr. med. Felicitas Heidler: Ökumenisches 
Hainich Klinikum gGmbH, Klinik für Neurologie, Mühlhausen; Dr. med. Michael Mandrysch: LWL-Klinik Lengerich, Abteilung Neurologie, Lengerich; Dr. med. Wolfgang Kusch: Herz-Jesu-Krankenhaus Hiltrup GmbH, Klinik für Neurologie, Münster; Dr. med. Alexander Niklas: Sana Klinikum Borna, Klinik für Neurologie, Borna; PD Dr. med. Hela-Felicitas Petereit: Praxis rechts vom Rhein, Köln; Dr. med. Jonas Repenthin: AMEOS Klinikum Oldenburg, Klinik für Neurologie und Neurophysiologie, MS-Ambulanz, Oldenburg/Holstein; Dr. med. Martin Brand: St. Augustinus Krankenhaus gGmbH, MVZ Medizinisches Versorgungszentrum GmbH, Praxis für Neurologie, Düren; Dr. med. Heike Stephanik: Otto-von-Guericke-Universität Magdeburg, Universitätsklinik für Neurologie/MS-Ambulanz, Magdeburg; Dr. med. Roland Bauer: Gemeinschaftspraxis für Neurologie Dr. Roland Bauer und Dr. Andrej Schleyer, Memmingen;

\section{Declarations}

Funding Open Access funding enabled and organized by Projekt DEAL. REGIMS is funded by the German Ministry of Research and Education (BMBF) within the German Competence Net Multiple Sclerosis (FKZ: 01GI1602E, 01GI0907). Co-funding is provided by Biogen (for the documentation of patients receiving natalizumab [Tysabri $\left.{ }^{\circledR}\right]$ ).

Conflict of interest AS and JT report a grant from the BMBF (within the German Competence Net Multiple Sclerosis) plus additional funds from Biogen, all to the University of Münster, during the implementation of the REGIMS registry. KB received a grant from the BMBF (within the German Competence Net Multiple Sclerosis) plus additional funds from Biogen, all to the University of Münster, for an investigator-initiated $\mathrm{AE}$ registry for patients with multiple sclerosis. HW received grants from the BMBF, Deutsche Forschungsgemeinschaft (DFG), Else Kröner Fresenius Foundation, Fresenius Foundation, the European Union, Hertie Foundation, NRW Ministry of Education and Research, Interdisciplinary Center for Clinical Studies (IZKF) Muenster and RE Children's Foundation, Biogen, GlaxoSmithKline GmbH, Roche Pharma AG, and Sanofi-Genzyme; consulting fees from AbbVie, Actelion, Biogen, IGES, Johnson \& Johnson, Novartis, Roche, and Sanofi-Aventis; support for travel to meetings for other purposes from AbbVie, Actelion, Biogen, IGES, Johnson \& Johnson, Novartis, Roche, and Sanofi-Aventis; fees for participation in review activities such as data monitoring boards from PSI CRO Deutschland $\mathrm{GmbH}$, and the Swiss Multiple Sclerosis Society; payment for lectures from Alexion, Biogen, Cognomed, F. Hoffmann-La Roche Ltd., Gemeinnützige Hertie-Stiftung, Merck Serono, Novartis, Roche Pharma AG, Genzyme, TEVA, and WebMD Global; and honorarium for expert testimony from Alexion, Biogen, Merck Serono, Novartis, and Genzyme outside the submitted work. He has filed patents no. SEP-103.3231/08, EP2769223, WO2013057092 (A1), and 15001186.4-1402. LK and SM have nothing to disclose.

Ethics approval Ethical approval was obtained for the study.

Consent to participate All patients enrolled in the REGIMS registry provided written informed consent at enrollment. The registry is conducted in accordance with the principles of the Declaration of Helsinki and is consistent with the International Council for Harmonization/ Good Clinical Practice.

\section{Consent to publish Not applicable.}

Data availability The datasets generated during and/or analyzed within the REGIMS registry are not publicly available because of the nature of the sensitive electronic medical data. Data from the KKNMS projects are available for scientific projects for network members as well as for other research institutions. The FaBIO committee of the KKNMS decides on the applications in a two-stage process. More information is provided on the website of the KKNMS: https://www.kompetenzn etz-multiplesklerose.de/en/research/fabio-2/

Code availability The code for the statistical analyses is available on request.

Study registration The project has been registered at the German Clinical Study Register (DRKS, Deutsches Register Klinischer Studien, no. DRKS00007190 and no. DRKS 00007127 [Tysabri® part]).

Author contributions AS: Drafted the manuscript for intellectual content; analyzed the data; interpreted the data; revised the manuscript for intellectual content. JT: Designed and conceptualized the manuscript; drafted the manuscript for intellectual content; interpreted the data; revised the manuscript for intellectual content. LK: Revised the manuscript for intellectual content; interpreted the data. SM: Coordinated the dataflow and managed the registry data; made substantial contributions to the acquisition of data; revised the manuscript for intellectual content. HW: Interpreted the data; revised the manuscript for intellectual content. KB: Interpreted the data; revised the manuscript for intellectual content. All authors read and approved the final version.

Open Access This article is licensed under a Creative Commons Attribution-NonCommercial 4.0 International License, which permits any non-commercial use, sharing, adaptation, distribution and reproduction in any medium or format, as long as you give appropriate credit to the original author(s) and the source, provide a link to the Creative Commons licence, and indicate if changes were made. The images or other third party material in this article are included in the article's Creative Commons licence, unless indicated otherwise in a credit line to the material. If material is not included in the article's Creative Commons licence and your intended use is not permitted by statutory regulation or exceeds the permitted use, you will need to obtain permission directly from the copyright holder. To view a copy of this licence, visit http://creativecommons.org/licenses/by-nc/4.0/.

\section{References}

1. WHO. Atlas of MS 2013 [Internet]. 2013. Available from: https ://www.msif.org/wp-content/uploads/2014/09/Atlas-of-MS.pdf. Accessed 24 Apr 2020.

2. Petersen G, Wittmann R, Arndt V, Göpffarth D. Epidemiologie der Multiplen Sklerose in Deutschland. Nervenarzt [Internet]. 2014;85:990-8. https://doi.org/10.1007/s00115-014-4097-4.

3. Morris K, Yiannikas C. Treatment Update in Multiple Sclerosis. Curr Allergy Asthma Rep [Internet]. 2012;12:246-54. https://doi. org/10.1007/s11882-012-0256-5.

4. Torkildsen $\varnothing$, Myhr K-M, B $\varnothing$ L. Disease-modifying treatments for multiple sclerosis - a review of approved medications. Eur J Neurol [Internet]. 2016;23:18-27. https://doi.org/10.1111/ene.12883.

5. Rommer PS, Milo R, Han MH, Satyanarayan S, Sellner J, Hauer L, et al. Immunological aspects of approved MS therapeutics. Front Immunol. 2019;10:1-24.

6. Faissner S, Gold R. Progressive multiple sclerosis: latest therapeutic developments and future directions. Ther Adv Neurol Disord [Internet]. 2019;12:175628641987832. https://doi. org/10.1177/1756286419878323.

7. Derfuss T, Mehling M, Papadopoulou A, Bar-Or A, Cohen JA, Kappos L. Advances in oral immunomodulating therapies in relapsing multiple sclerosis. Lancet Neurol. 2020;19(4):336-47. https://doi.org/10.1016/S1474-4422(19)30391-6. 
8. Competence Network Multiple Sclerosis. Kompetenznetz Multiple Sklerose (Competence Network Multiple Sclerosis) [Internet]. [cited 2020 Aug 13]. https://www.kompetenznetz-multipleskleros e.de/en/. Accessed 13 Aug 2020.

9. Hillert J, Stawiarz L. The Swedish MS registry-clinical support tool and scientific resource. Acta Neurol Scand. 2015;132:11-9.

10. Richter A, Meißner Y, Strangfeld A, Zink A. Primary and secondary patient data in contrast: the use of observational studies like RABBIT. Clin Exp Rheumatol. 2016;34:79-86.

11. Pombo-Suarez M, Gomez-Reino J. The role of registries in the treatment of rheumatoid arthritis with biologic disease-modifying anti-rheumatic drugs. Pharmacol Res. 2019;148:104410.

12. Curtis JR, Jain A, Askling J, Bridges SL, Carmona L, Dixon W, et al. A comparison of patient characteristics and outcomes in selected European and U.S. Rheumatoid Arthritis Registries1. Semin Arthritis Rheum. 2010;40:2-14.e1.

13. Uitdehaag BMJ, Barkhof F, Coyle PK, Gardner JD, Jeffery DR, Mikol DD. The changing face of multiple sclerosis clinical trial populations. Curr Med Res Opin. 2011;27:1529-37.

14. Zhang Y, Salter A, Wallström E, Cutter G, Stüve O. Evolution of clinical trials in multiple sclerosis. Ther Adv Neurol Disord [Internet]. 2019;12:175628641982654. https://doi.org/10.1177/17562 86419826547.

15. Blecha S, Thomann-Hackner K, Brandstetter S, Dodoo-Schittko F, Seboek P, Apfelbacher C, et al. Die Rolle von Ethikkommissionen für die nationale Versorgungsforschung - eine Querschnittsstudie des Aufwandes zur Erlangung von Sekundärvoten anhand der DACAPO-Studie. DMW Dtsch Medizinische Wochenschrift [Internet]. 2015;140:e186-e193193. https://doi. org/10.1055/s-0041-103170.
16. Eichler M, Schmitt J, Schuler MK. Die Dauer von Ethikvoten in Deutschland - am Beispiel einer nicht-interventionellen Beobachtungsstudie mit 44 teilnehmenden Zentren (PROSa). Z Evid Fortbild Qual Gesundhwes [Internet]. 2019;146:15-20. https://linki nghub.elsevier.com/retrieve/pii/S1865921719300996. Accessed 24 Apr 2020.

17. Flachenecker P, Stuke K, Elias W, Freidel M, Haas J, PitschnauMichel D, et al. Multiple Sclerosis Registry in Germany Results of the Extension Phase 2005/2006. Dtsch Arztebl Int. 2008;105:113-9.

18. Kobelt G, Berg J, Lindgren P, Berger K, Elias WG, Flachenecker $\mathrm{P}$, et al. Costs and quality of life of multiple sclerosis in Germany. Eur J Heal Econ. 2006; 7:34-44.

19. Stuke K, Flachenecker P, Zettl UK, Elias WG, Freidel M, Haas J, et al. Symptomatology of MS: results from the German MS Registry. J Neurol [Internet]. 2009;256:1932-5. https://doi.org/10.1007/ s00415-009-5257-5.

20. Costello K, Kennedy P, Scanzillo J. Recognizing nonadherence in patients with multiple sclerosis and maintaining treatment adherence in the long term. Medsc J Med [Internet]. 2008;10:225. https ://www.ncbi.nlm.nih.gov/pubmed/19008986. Accessed $24 \mathrm{Apr}$ 2020.

21. Lugaresi A, Ziemssen, Oreja-Guevara, Thomas, Verdun. Improving patient-physician dialog: commentary on the results of the MS Choices survey. Patient Prefer Adher [Internet]. 2012;143. https ://www.dovepress.com/improving-patientndashphysician-dialo g-commentary-on-the-results-of-th-peer-reviewed-article-PPA. Accessed 24 Apr 2020. 